\title{
Research on the Application of Educational Incentive Mechanism in Class Management in Primary Schools
}

Linzhi Tao*

Zhejiang University of Finance \& Economics Dongfang College, Jiaxing 314400, Zhejiang province, China. Email: 1582309455@qq.com.

Abstract: Improving the level of primary school class management can effectively adapt to the development of modern basic education in China; as an efficient means of class management, educational incentives are effective for students' academic progress, teacher professionalism, class management efficiency, friendly teacher-student relationship, and school innovation and development. There's important meaning. Through the analysis of the current situation of the application of educational incentive mechanism in elementary school class management, in view of the problems of teachers who have not fully mastered the incentive mechanism, the incentive strategy does not meet the needs of students and the single incentive model, etc. It is proposed that re-education improves teachers' comprehensive ability in class management, teaching students in accordance with their aptitude to strengthen communication between teachers and students, changing the way of thinking to promote the diversification of incentive methods.

Keywords: Motivation; Class management; Primary education

\section{Introduction}

Class is the basic unit of school education and the main place for students and teachers to communicate. Class management, as a purposeful and planned social activity, is the fundamental guarantee for achieving educational goals and improving teaching quality. Primary school students are still young in age and qualifications, and they are in a crucial period of world outlook, outlook on life, and value formation ${ }^{[1]}$. The success of class management directly affects students' physical and mental development, academic performance and moral quality, and it's also determines teacher-student relationship and class atmosphere, as well as the overall development of school education and teaching.

In modern society, with the continuous development and innovation of educational incentive theory, educational incentive mechanism has gradually replaced the traditional management model and has become one of the commonly used class management methods for teachers ${ }^{[2]}$. Scientific and effective incentive strategies can stimulate students' intrinsic motivation and potential abilities to a large extent, promote students' autonomous learning, improve class management efficiency and ultimately realize student autonomy ${ }^{[3]}$. At present, educational incentive mechanism still has many challenges in the management of elementary school classes; therefore, it is of great significance to research the application of incentive mechanism by elementary school teachers in class management and to put forward reasonable suggestions $^{[4]}$.

\section{The application status and existing problems of educational incentive in primary school class management}


According to relevant literature records, the initial motivation theory was put forward by Western scholars in the early 20th century, and the initial research on motivation theory in my country began in the 1980s, and the initial research object was aimed at enterprise employees; it was in the 1990s that the motivation theory was introduced into the education sector, and then continued to grow and develop ${ }^{[5]}$. In recent years, the application of motivation theory knowledge has penetrated into the management of all walks of life in our country, and has achieved remarkable results. However, due to the differences in national conditions and actual conditions in various countries, we cannot copy the research results of Western motivation theory ${ }^{[6]}$. There are still some problems with the application of educational incentive mechanism in elementary school class management due to China lacks a systematic incentive theory system.

\subsection{Teachers do not fully grasp the incentive mechanism}

Some teachers' motivation theory is not solid, their opinions are one-sided, and their concepts and methods of use are not clear. They cannot effectively distinguish the difference between "motivation" and "encouragement". There are also teachers who only understand and use incentives from the motivation level of educational psychology, without combining management knowledge, and lack of comprehensive professional capabilities. Because there is no professional theory support, it is impossible to scientifically and efficiently use educational incentive mechanism to make it play a real role in class management, which is not conducive to the sound development of primary school class management $^{[7]}$. For example, some teachers blindly use positive incentives in motivation, only knowing encouragement and praise, but they do not combine negative incentives to let students learn to grow and improve themselves.

\subsection{Motivation strategies do not meet the specific needs of students}

Firstly, the use of educational incentive mechanisms in some schools is only a forma of content, so the incentive effect is weak. Secondly, teachers cannot take care of everyone due to face a large number of students. What's more, teachers often encourage only a small number of outstanding students. However, elementary school students attach great importance to the evaluation of teachers, and the imbalance of incentives will give others psychological pressure and gap, which is not conducive to the formation of class unity and good atmosphere. Thirdly, there is little in-depth communication between teachers and students which lacks of individualized and personalized teaching, and insufficient understanding of the specific needs of students. Therefore, teachers' motivation strategies are often different from what students expect. And the motivation effect will be greatly reduced, which will produce a vicious circle in the long run ${ }^{[8]}$.

\subsection{Single incentive model and lack of innovation}

First of all, as a relatively traditional mode of motivation, teachers tend to choose students with excellent academic performance in the class as their role models. But the target is single, the teacher just regards academic performance as the only criterion, and lacks encouragement for students with expertise in other fields. If the role model has been out of reach, its incentive effect will gradually decrease, which is not conducive to the comprehensive development of students in all aspects and multiple fields, and the formation of class cohesion.

Secondly, as one of the most convenient motivation methods, language motivation is hardly restricted by places and other conditions. However, the motivational language content of teachers is single, mostly simple praise, without in-depth explanation of the reason, and the content is repeated. Over time, students will become fatigued and less motivated $^{[9]}$.

Finally, teachers did not closely combine internal and external co-motivation, positive and negative co-motivation, human-based fair co-motivation, and individual collective co-motivation. The use of various incentive methods is affected by traditional management models and lack of innovation.

\section{Countermeasures and suggestions for the use of incentive mechanism in primary school class management}

\subsection{Re-education to improve teachers' comprehensive ability in class manage-}




\section{ment}

The scientific nature of class management largely depends on the professional quality of teachers, so it is imperative to strengthen the comprehensive ability of primary school teachers and build a team of high-quality teachers. What needs to be clearly clarified is that class management is not only aimed at the primary school head teacher, but all teachers should also have the ability to assist. In addition, teachers must not only improve the professional competence in education and teaching, but also strengthen the organization of students, evaluation, communication, management and other aspects of capacity.

On the one hand, schools should regularly organize teacher learning, exchanges, relevant course training and assessments to help them consolidate theoretical knowledge and improve class management skills. On the other hand, teachers should take the initiative to learn laws and regulations, incentive theories and professional knowledge of class management. Through multi-field and multi-level research, they can enhance ideological realm and comprehensive ability. And in practice, according to the characteristics of students, classes gradually improve the incentive mechanism by accumulated experience, continuous exploration and improvement.

\subsection{Teach students in accordance with their aptitude and strengthen communi- cation between teachers and students}

Scientific motivational strategies should be carried out after understanding the personality characteristics and specific needs of students. The most efficient way is to communicate with students in depth. Studies have shown that most students expect teachers' evaluation and emotional communication, so they pay more attention to students' psychological ideas. Therefore, strengthening the two-way communication between teachers and students is particularly crucial. Teachers can communicate with each student privately on a regular basis, discover and solve the difficulties encountered by students in time, and continuously encourage and improve students'subjective initiative.

Secondly, every student has different characteristics in personality, ideas and interests, because the growth environment and experience are various. Therefore, teachers should be student-oriented, respect students' differences, protect students' self-esteem and self-confidence, and teach students in accordance with their aptitudes ${ }^{[10]}$. Various incentive strategies are used for different students in order to maximize their potential. For example, when talking with different students, they emphasize diverse content and language expressions, corresponding plans and target direction guidance according to the learning situation of different students.

\subsection{Change thinking and promote diversification of incentive methods}

\subsubsection{Diversify role model incentives}

Models can be used as a beacon to guide students in the direction of progress. Diversification of role models can guide students to comprehensive development. First of all, the main task of teachers is to teach and educate people, and their words and deeds directly affect student behavior and class atmosphere. Therefore, teachers need to do a good role model, establish a good image for students, and take the lead. Secondly, teachers can select outstanding behaviors, high moral character, excellent academic performance, obvious learning progress, professional skills and expertise in different fields of morality, intelligence, physical education and labor as student role models to encourage students to follow and try to be a part of them. Finally, not limited to the school, teachers can take the outstanding deeds and figures in society as the role model objects of students, learn their character and ideas and inspire students to improve themselves with the overall situation and development perspective.

\subsubsection{Diversify emotional motivation methods}

On the one hand, teachers should be good at using the art of language, always pay attention to the state and physical and mental development of students, communicate with students with sincere and warm words. They need to be positive when their students are doing well and, and guide them to correct their mistakes. In teaching, teachers can attach importance to rigidity and flexibility together, as well as combine the positive and negative incentives effectively. On the other hand, teachers can use non-verbal skills such as expressions and movements to convey affirmative and supportive eyes to students, so that students can feel encouragement and care. The relationship between teachers and 
students will become more intimate through above methods.

\subsubsection{Target encourages diversification of content}

First of all, teachers can give full play to the initiative of students according to the overall situation of the class, let students participate in the formulation of the overall goal of the class collective, and enhance class cohesion. Secondly, teachers can formulate the overall goal of individual struggle according to the different situations of each student, and help each student to have a clear plan. Then, in accordance with each student's overall goal, teacher can assist them in setting their own milestones, familiarizing themselves with their own development plans and constantly striving for them. Finally, teachers should be able to evaluate the achievement of their students' and class's goals, so that everyone can feel the results of their own efforts, learn from experiences and make continuous progress.

\section{Conclusion}

In summary, the rational use of educational incentive mechanisms can effectively improve the level of class management and promote the development of modern basic education in China. Facing the existing problems, elementary school teachers need to take education motivation theory as the guiding philosophy, uphold the principle of fairness and justice, respect the differences of students, pay attention to teaching in accordance with their aptitude, pay attention to the psychology of students, strengthen communication with students and stimulate students' vitality and creativity. In addition, we anticipate that they can improve the incentive mechanism through the joint action of teachers and students to raise the efficiency and level of class management.

\section{References}

1. Cui H. Research on the application of incentive mechanism in primary school class management. China Rural Education 2020; (05): $37-38$.

2. Huang G. Talking about the application of incentive mechanism in the management of elementary school classes. China Rural Education 2019; (30): 44 - 45.

3. Li L. How to build an incentive mechanism in elementary school class management. Scientific Consulting (Technology $\cdot$ Management) 2020; (07): 43.

4. Ma Y. Investigation and research on motivation strategies in the management of lower grades in primary schools. Shenyang Normal University 2020.

5. Ma X. The application of people-oriented management model in elementary school class management. Examination Weekly 2020; (A5): 13 - 14.

6. Wang Y. Inquiry into the incentive style of the head teacher in the management of the senior class in primary school. Xi'an International Studies University 2018.

7. Xiong J. Strategies to improve the effectiveness of primary school class management. Scientific Consulting (Education and Research) 2020; (09): 200.

8. Yao Z. Research on class management strategies in primary schools. Examination Weekly 2021; (02):151 - 152.

9. Zhao Q, Li Y. The use of incentive mechanism in the management of elementary school classes. Quality Education in West China 2020; 6(10): 254 - 256.

10. Zhang Y. Research on incentive application in primary school class management. Fujian Normal University 2018. 